\title{
"YA NO TIENEN DONDE MORIR LAS OFELIAS". DOS AUTORAS EN LA BARCELONA DE LA VANGUARDIA: ELISABETH MULDER Y ANA MARÍA MARTÍNEZ SAGI
}

\author{
"YA NO TIENEN DONDE MORIR LAS OFELIAS". TWO WOMEN WRITERS \\ DURING THE AVANT-GARDE IN BARCELONA: ELISABETH MULDER AND \\ ANA MARÍA MARTÍNEZ SAGI
}

Fran Garcerá

\section{Resumen:}

El presente artículo estudia las redes de colaboración entre las escritoras Elisabeth Mulder y Ana María Martínez Sagi, tanto entre ellas como con otros agentes del campo cultural, durante la Edad de Plata. Para ello, se analizarán los diferentes elementos paratextuales de las obras poéticas que publicaron en esta época y otros materiales de carácter inédito, como su correspondencia con las escritoras Gabriela Mistral y Carmen Conde.

\section{Palabras Clave:}

redes de colaboración, paratextualidad, Elisabeth Mulder, Ana María Martínez Sagi

\section{Abstract:}

This article presents the network between women writers Elisabeth Mulder and Ana María Martínez Sagi, as well as with other writers and journalists, among others, during the Silver Age. This article analyzes the different paratextual elements of their books of poems published at this time and other unpublished materials, such as their correspondence with the women writers Gabriela Mistral and Carmen Conde.

\section{KeYwORDS:}

women networks, paratextuality, Elisabeth Mulder, Ana María Martínez Sagi 


\section{INTRODUCCIÓN}

Barcelona constituyó un segundo centro cultural alejado del radicado en Madrid durante la Edad de Plata, pero en constante comunicación e intercambio con la urbe capitalina ${ }^{1}$. Este hecho se ve en la proliferación de instituciones femeninas que se crearon siguiendo el modelo instaurado en Madrid. Entre otras, estas fueron la Residència Internacional de Senyoretes Estudiantes de la Generalitat de Catalunya, fundada el 1 de octubre de 1931, y el Lyceum Club de Barcelona, inaugurado también ese mismo año. De hecho, en la página 4 del diario La Publicitat de la capital condal, publicado el día 7 de julio de 1931, puede leerse el texto fundacional del mismo, titulado "Manifest a les dones", que dice:

Amb el nom de "Lyceum Club" de Barcelona, acabem de fundar a la nostra ciutat una agrupació femenina que té per base els principis democràtics de llibertat $\mathrm{i}$ d'igualtat, ensems que un afany intens de cultura.

La nostra agrupació no aspira a ésser una societat més on les dones d'esperit més o menys selecte es reuneixen per a prendre una tassa de te, fullejar un magazine, sentir un petita conferència o un concert íntim, ni tampoc a esdevenir un grup de dones, amarades d'indignacions, poc o molt santes, que volen fer la guerra a l'home, reclamar tota mena de drets i llançar la flama abrandada, del més ferotge feminisme.

Ni una cosa ni l'altra, però un poc de cada una.

Volem acoblar-nos sota el lema de "llibertat i cultura" i educar-nos i instruir-nos sobre aquests aspectes concrets: Política, Dret, Higiene, Sociologia econòmica i moral, Art i Literatura, procurant-nos aquests ensenyaments per mitjà de cursets, conferències, converses, especialitzacions encomanades a tècnics de dintre o de fora del Club, però de reconeguda solvència. I sobretot, desitgem a la dona per ferla un poc menys desvalguda, instruint-la, procurant-li coneixements sobre higiene, lleis, l'abast dels seus drets, moral, economia i política.

En una paraula, contribuir amb totes les nostres forces a treure la dona del poble de la terrible ignorància que l'aclapara.

La mayor diferencia entre los Lyceum de Madrid y Barcelona fue, precisamente, su elitismo. Mientras que el primero tuvo entre sus miembros un rasgo de clase social privilegiada - sus socias pertenecieron a la alta burguesía o la aristocracia-, el de Barcelona tuvo entre sus objetivos educar a todas las mujeres, puesto que se entendía que solo a través de la adquisición de la cultura estas podrían mejorar su situación social. En este sentido, en su manifiesto fundamental, se alegaba que:

No li demanem més que una petita atenció de tant en tant i li consagrarem les més belles hores de les nostres vides.

Preguem, doncs, a totes les dones de bona voluntat, que se sentin aptes per a fer obra de cultura i sociologia, o simplement que simpatitzin amb els nostres ideals, que vulguin ajuntar-se amb nosaltres per a treballar intensament de cara a la

1 Esta publicación se incluye en el marco de los proyectos de I+D+i FFI2016-76037-P y PID2019104004GB-I00. 
nostra perfecció moral, espiritual i intel.lectual i tot seguit, -un cop degudament orientades- de cara al poble per ajudar-lo en tot allò que calgui.

"Lyceum Club" de Barcelona no vol rivalitzar amb cap altra entitat, al contrari: aspira a ésser un factor més del gran producte femení, encara inèdit.

“Lyceum Club" té un amplíssim programa a complir i el complirà, fidel a les normes que l'han engendrat.

Dones, estudieu aquest manifest, demaneu els nostres Estatuts; ells us diran prou clar dels nostres anhels i si us sentiu amb cor de compartir-los amb nosaltres, acobleu-vos al "Lyceum Club".

Això ens farà a totes més fortes.

Signen: Aurora Bertrana, Maria Pi de Folch, Enriqueta Sèculi, Anna Miret, Carme Cortès d'Aiguader, Mercè Ros, Montserrat Graner de Bertran, Isolina Viladot, Leonor Serrano de Xandri, Maria Carratalà, Josefina Bayona de Cortès i Amanda Llebot.

Asimismo, una de las firmantes, Aurora Bertrana, fue miembro del Club Femení i d'Esports de Barcelona, que fue fundado en 1928 y constituyó la primera asociación deportiva exclusivamente femenina de España (Real Mercadal 1988). Por lo tanto, la ciudad de Barcelona se consolidó como un segundo centro de reivindicación femenino con sus particularidades y objetivos propios.

Fue en este contexto cultural donde desarrollaron sus vocaciones autorales Elisabeth Mulder y Ana María Martínez Sagi, hasta el punto de que Mulder ejerció una especie de tutela literaria sobre la segunda, fundamentada en una estrecha relación y una red de apoyo basada no solo en la sororidad sino, sobre todo, en el afecto. Aunque, como veremos, sus redes literarias sobrepasaron las fronteras de su ciudad natal y se extendieron hacia un gran grupo de autores de toda la geografía española, sobre todo, en el caso de Mulder.

\section{2. "Hoy lo SÉ: SE llamaba vocación". UNA POETa IRRUMPE EN EL PANOrAma literario: Elisabeth MUlder}

Elisabeth Mulder vino al mundo entre 1903 y $1904^{2}$, en una familia de la alta burguesía en Barcelona. Sus primeros años los pasó en una hacienda cafetera en Puerto Rico, propiedad de su familia materna que tenía ascendencia catalana e italiana. Lo mismo ocurrió con su padre, un holandés de madre española, que le legó el Marquesado de Tedema Toelosdorp en los Países Bajos, aunque la escritora nunca hizo uso del mismo (Mañas 1988: 11-12). El relato de sus primeros años de aprendizaje lo encontramos en el testimonio que la poeta dejó en el volumen El autor enjuicia su obra de 1966, donde diversos escritores como Mercedes Salisachs (1916-2014), Gerardo Diego (1896-1987)

$2 \quad M^{a}$ del Mar Mañas, en su Tesis doctoral sobra la obra narrativa de la escritora, apunta que Mulder fue inscrita en fechas distintas en el Registro Civil de España y en el del consulado de Holanda. Su hijo, Enrique Dauner Mulder, en una entrevista con la investigadora, se inclinó por la fecha más temprana, puesto que ni la propia Elisabeth Mulder supo con exactitud en qué año se produjo su nacimiento (Mañas 1988). 
o Ana María Matute (1925-2014), entre otros, dejaron curiosas opiniones sobre su quehacer literario, a partir de las conferencias que estos mismos dictaron en el Ateneo de Madrid durante el año 1965. De este modo, Elisabeth Mulder dio cuenta de su dificultad para aprender a leer, puesto que:

[...] yo casi aprendí antes a escribir que a leer, y que si dominé rápidamente el juego de combinar las palabras formando frases, en cambio llegar a conocer las letras y formar las palabras fue un proceso largo, incluso doloroso por la tensión a que me sometía. No he conocido jamás a una criatura más torpe, más densa para las letras ni más temerosa de ellas que yo. [...] Ahora bien, en cuanto yo tuve la facultad de mover aquel resorte mágico, o sea de construir palabras que tienen un sentido, con aquello dibujitos impenetrables hasta entonces que eran las letras, el misterio de la expresión escrita se me abrió de pronto, deslumbrante, como una arca tosca y extraña cuya tapa, al alzarse, deja ver el más soberbio tesoro de pedrerías y metales precioso. Allí hundí mis manos en el acto con un voraz deseo de posesión. Manejar aquel mundo increíble, aquella materia fabulosa, constituía para mí un apasionante juego cuyo nombre yo ignoraba entonces. [...] Hoy lo sé: se llamaba vocación. Y la niña torpísima que tanto tardó en saber leer, tardó tan poco en saber escribir que a los siete años, a la misma edad en que aprendió a hacerlo, materialmente escribió su primer cuento, de argumento real, basado en un suceso de su propia familia (AA. VV. 1966: 192).

La educación de Elisabeth Mulder se produjo a través de preceptores particulares y tan solo asistió al colegio unos pocos meses, con motivo de la preparación de su primera comunión. No obstante, su gusto por el viaje - compartido con su padrefacilitó su aprendizaje del francés, el italiano y, sobre todo, el inglés, que aprendió a la vez que el castellano. Años después, incluso, la lengua en la que se comunicaba con su hijo en casa fue la inglesa. De hecho, "su primer trabajo periodístico fue en una sección de literatura inglesa en el diario El Noticiero Universal de Barcelona" (Mañas 1988: 13). Otro idioma que dominó, extraño en el aprendizaje de sus coetáneos, fue el ruso, gracias a una de sus preceptoras, quien había sido antigua dama de la Zarina Alejandra y, tras las revoluciones acaecidas en Rusia en 1917, había fijado su residencia en la ciudad de Barcelona. Asimismo, como otras muchachas de su tiempo, cultivó diferentes deportes como el tenis, el patinaje, la equitación o la natación, con cuya práctica obtuvo un campeonato en su ciudad natal (Mañas 1988: 14).

La vocación autoral de Elisabeth Mulder, como ya vimos, fue temprana. En este sentido, a los quince años ganó el Primer Premio en los Juegos Florales celebrados en Barcelona con su poema titulado "Circe". Algunos de esos primeros poemas se conservan en el archivo personal de la escritora custodiado por su familia, al que tuvimos acceso durante nuestra investigación. Estas composiciones las firmó con el pseudónimo Esfinge y publicó algunas de ellas en la revista barcelonesa Sabor y Aroma en torno a 1920 y 1921 (Mañas 1988: 17). Fue en ese último año cuando se produjo su matrimonio con Ezequiel Dauner, un hombre treinta años mayor que ella, seguramente, 
por imposición de su familia (Prada 2018: XV). Pese a su temprana edad, en 1923, se produjo el nacimiento de su único hijo.

No fue hasta 1927 cuando publicó su primer poemario, Embrujamiento. Al año siguiente, dio a las prensas su segundo libro de poemas, La canción cristalina. Aunque en estos dos libros prescindió de cualquier elemento paratextual, reflejo de su fuerte sentimiento de independencia literaria. Sí cabe reseñar que el lugar elegido para estas dos obras fue la Editorial Cervantes de Barcelona, fundada en 1916 por Vicente Clavel Andrés (1888-1967)³ , quien se había formado en la editorial valenciana Prometeo de Vicente Blasco Ibáñez (1867-1928) y Francisco Sempere (1859-1922)4 . La elección de esta empresa por parte de Elisabeth Mulder no es casual puesto que la Editorial Cervantes tuvo como una de sus marcas distintivas la edición de poesía. De este modo, indica Luis Miguel Lázaro que:

Ja en el primer any de funcionament de l'editorial es publica una obra que serà prompte reeixida, Las cien mejores poesías (líricas) de la lengua francesa, "admirablemente" traduïdes directament en vers -com li agrada a Díez Canedoper Maristany, amb qui Clavel tindrà en els anys següents fins a la seua mort en 1924 una regular i intensa col-laboració professional. En 1918 manté la seua inequívoca aposta editorial per la poesia amb l'edició de Las cien mejores poesías (líricas) de la lengua portuguesa, traduïdes directament en vers per Maristany, amb pròleg d'Ignasi Ribera i Rovira, i Las cien mejores poesías (líricas) de la lengua inglesa, recopilades i traduïdes en vers castellà també per Maristany amb un pròleg d’Enrique Díez Canedo (Lázaro 2013: 42-43).

Esta colección de poesía en particular hizo que Editorial Cervantes ganase en popularidad entre el público lector afín a este género. Además, logró que:

En l'oferta de textos de poesia de l'editorial la reeixida i popular col-lecció Las Mejores Poesías (Líricas) de los Mejores Poetas té, sens dubte, un paper central. Les tirades, d'entre 3.000 i 8.000 exemplars per a un total de 63 tomets de prop de seixanta pàgines de mitjana, que es venien per entre 1 i 4,50 ptes., fins a 1932 coneixeran successives reedicions de molts dels títols (Lázaro 2013: 44).

Este éxito editorial hizo que Editorial Cervantes publicase Prisma. Prevista Internacional de Poesía que, bajo la dirección del poeta mexicano Rafael Lozano, entre enero y agosto de 1922, publicó dos volúmenes de cuatro números cada uno. En esta participaron autores como:

[...] Alfons Maseras, Juan Ramón Jiménez -números 1 i 3- i Gregorio Martínez Sierra i d'alguns dels autors de la col-lecció Las Mejores Poesías (Líricas) de los Mejores Poetas, com Teixeira de Pascoaes, Gabriela Mistral, Hrand Nazariantz,

3 Respecto al mundo editorial catalán, puede consultarse la obra elaborada por Manuel Llanas, en colaboración con Montse Ayats, L'edició a Catalunya: el segle XX (fins a 1939) (2005).

4 Respecto a la Sociedad Editorial Prometeo, remitimos a Javier Lluch (2010 y 2017). 
Juana de Ibarbourou, Juan Maragall, Paul Fort, Salvador Albert i Pey, Constantin Balmont, Edgar Allan Poe, Percy Bysshe Shelley, i Paul Verlaine. Publiquen articles per donar a conèixer la nova poesia bolxevic, algeriana, polonesa, holandesa i nordamericana, i tenen una secció fixa per presentar nous valors i obres, Los Poetas que Surgen, de la qual s'encarrega un autor diferent en cada número (Lázaro 2013: 44-45).

Entonces, no es de extrañar que Editorial Cervantes resultase un lugar atractivo para que una poeta novel quisiera dar a conocer su obra. Además, Elisabeth Mulder no se conformó con publicar en esta su tercer y su cuarto poemario, sino que ejerció de prologuista y traductora de algunos de sus títulos. De esta forma, su director, Vicente Clavel, fue testigo de cómo:

Al llarg dels anys vint, l'editorial incrementa el seu patrimoni de poesia editada amb les obres d'Alice Lardé de Venturino, El Nuevo Mundo Polar; Salvador de Madariaga, La fuente serena (Cantos, romances líricos y sonetos a la española); Mariano de las Cuevas García, Los rosales florecen; Braulio Sánchez Sáez, Viento del Brasil y otros poemas; Luisa Luisi, Poemas de la inmovilidad y canciones al sol, i Narciso Díaz d'Escovar, Guitarra andaluza. En 1927 de Pedro Luis de Gálvez, publica Poesías seleccionadas i, d'Elisabeth Mulder de Dauner, poeta catalana simbolista i noucentista, traductora i prologuista de l'editorial, Embrujamiento, de 1927. Continuarà publicant l'obra d'aquesta autora en anys posteriors; La canción cristalina en 1928; Sinfonía en rojo en 1929, i La hora emocionada en 1931. I en 1930, amb pròleg de Gabriela Mistral, publica Boletines de mar y tierra, de Jorge Carrera Andrade (Lázaro 2013: 45).

Es en su tercera obra poética de 1929, Sinfonía en rojo, donde encontramos el primer elemento paratextual reseñable: un pórtico de la periodista y escritora María Luz Morales (1889-1980). Como en otros casos, su autora ensalza la labor literaria de Mulder al aducir la ausencia de voces femeninas en la Historia de nuestra literatura:

Al lado de pensadoras, de sociólogas, de novelistas eminentes, nótase más aún el hueco que en nuestras letras no llena una clásica Safo antigua, ni una delicada Marcelina Desbordes romántica, ni una poética y humana Ada Negri moderna. Hay, claro, el milagro de Santa Teresa. Más como la Mística, como nuestra Mística toda, la obra de la Virgen de Ávila, de la Santa andariega, es eso: un milagro. Y los milagros caen fuera, están por encima de las Antologías. Después, nada. Gertrudis Gómez de Avellaneda, en su aspecto lírico pertenece, más que a España, a América, a su patria. Rosalía de Castro, nuestra dulce y torturada Rosalía, como las poetisas catalanas y portuguesas, si hermanas nuestras en iberismo, tienen su lugar en otras literaturas, pues que jamás su ritmo de poesía se derramó en molde de habla castellana. Los intentos poéticos de Fernán Caballero no añaden una brizna de valor a su gran figura de gran flok-lorista [sic] e interesantísima mujer. Los de la insigne Pardo Bazán... más, en bien de su recuerdo, tan representativo, olvidarlos... [...] La mujer moderna de España trae la aportación nuevecita, flamante, intocada de su antorcha de amor y dolor y poesía, a la hoguera perenne de la lírica de todos los países y todos los tiempos.

He aquí la Poesía, delicia y tormento sagrado. He aquí la luminaria que —ibien alta, bien alta! - levanta el brazo ágil y bello de esta musa atormentada y crepitante que es Elisabeth Mulder (en Mulder 1929: 6-8). 
En este sentido, Morales apunta a que lo importante es la palabra por encima del género de quien la produzca, sobre todo, si la voz poética es personalísima, por lo que se pregunta:

¿Qué importa lo que la Mujer seo o no sea? El Poeta es lo que importa y el verso lo que, en esencia, es. [...] Es, pues, en el verso, en los versos - “isolo en ellos soy yo!" - donde debemos buscar al Poeta, y con él fundida y engranada, a la Mujer. ¡El verso, los versos de Elisabeth Mulder! [...] Elisabeth Mulder es, a mi juicio, ante todo y sobre todo, la musa sincera (en Mulder 1929: 10-11).

A continuación, Morales justifica la ausencia de prólogos en los dos primeros libros de Mulder, no por falta de apoyos literarios y culturales, puesto que:

Los dos primeros libros -Embrujamiento, La canción cristalina- de Elisabeth Mulder, fueron lanzados al gran público en un gesto valiente, sin coraza ni escudo de Prólogo, ni Pórtico, ni preparación... A quererlo, no le hubiesen negado las más altas autoridades literarias el apoyo de su prestigio. Pero ella no lo quiso; y nos dio su libro desnudo, desvelado, como su Poesía, en actitud a un tiempo de humildad y de altivez... Ahora: ¿no es aún mayor humildad querer que a esta magnífica Sinfonía en Rojo le ponga introducción mi débil voz?

[...]

He aquí Sinfonía en rojo de Elisabeth Mulder. He aquí la Poesía. Entrad... (en Mulder, 1929: 13-14).

La elección de María Luz Morales no es casual. Esta se incorporó como directora de la revista El Hogar y la Moda, de la cual surgió la revista Lecturas. Incluso, llegó a ser directora del diario La Vanguardia de agosto de 1936 a febrero de 1937 en plena Guerra Civil (Cabré 2017: 19-27). La amistad que unió a ambas mujeres fue tan estrecha que, incluso, llegaron a escribir de manera conjunta la obra de teatro Romance de medianoche, estrenada en el teatro Arriaga de Bilbao y en la que la actriz argentina Josefina Díaz de Artigas (1891-1976) representó el papel protagonista (Prada 2018: xx-xxi). De hecho, entre los años 1930 y 1935, Mulder colaboró mediante la publicación de relatos en las revistas Lecturas y Brisas (Mañas 1988: 18). Asimismo, Elisabeth Mulder comenzó a configurar una red extensa de contactos con otros escritores, pese a su férrea independencia de círculos literarios y adscripciones políticas, más allá de su ciudad. Por ejemplo, en Madrid, contó con la amistad de:

Concha Espina, Jacinto Benavente, Julián Marías, el Padre Blanco García, Matilde Marquina, la Condesa de Campo Alange, Gerardo Diego, Dolores Medio, y sobre todo Consuelo Berges con quien, cuando su delicada salud le impedía desplazarse, mantenía larguísimas conversaciones telefónicas. Mantuvo además relación epistolar con Colette, Jean Cocteau, y Max Aub con el que mantenía buena amistad desde antes de su exilio. Conocía desde pequeña y admiraba a H.G Wells y en su biblioteca tenía libros suyos dedicados como el Esquema de la Historia aparecido en España en la editorial Atenea (Mañas 1988: 25). 
Asimismo, a través de su amistad con María Luz Morales, entró en contacto con la Residència Internacional de Senyoretes Estudiantes de la Generalitat de Catalunya, fundada el 1 de octubre 1931 y cuya dirección recayó, precisamente, en Morales, de quien había partido la iniciativa un año antes (Real Mercadal, 2006: 209). Además, a partir de 1932, se creó un intercambio anual de estudiantes entre esta y la Residencia de Señoritas de Madrid. De hecho, la Residència tuvo como huésped a la poeta Gabriela Mistral en su sede del Palau de Pedralbes (Mañas, 1988: 26). Fue en esta época cuando Elisabeth Mulder envió una carta a Gabriela Mistral junto a sus publicaciones, en un intento por establecer un vínculo con ella, justo en el mismo periodo en el que la escritora Carmen Conde entabló una amistad más profunda con la chilena y esta le prologó su libro Júbilos ${ }^{5}$. De esta forma, en la misma puede leerse lo siguiente:

17 agosto 1933

Doña Gabriela Mistral.

Excelsa poetisa:

Tengo el gusto de enviar a usted mis libros, no por el interés artístico que tengan, pues desgraciadamente este es nulo, sino porque ellos son portadores de mi admiración a usted $\mathrm{y}$, aunque humilde, constituyen un fervoroso homenaje de entusiasmo y de afecto.

La saluda atentamente su devota lectora

Elisabeth Mulder

S/C Paseo de la Bonanva, 53.

Barcelona $^{6}$

De momento, no hay constancia documental de que la relación entre ambas fuera mucho más que un amable intercambio epistolar. De hecho, la siguiente carta de Mulder a Mistral data del 8 de junio de 1938, en la que la poeta barcelonesa le indica que:

Le mando estas líneas un poco al azar, sin saber si llegarán a sus manos, pues ignoro el tiempo que permanecerá usted en Buenos Aires.

Le escribí a París hace ya tiempo y no obtuve respuesta. Si esta vez fuera más afortunada, ¡qué alegría!

Su recuerdo y sus libros me acompañan siempre. Esto hará que cuando volvamos a encontrarnos, algún día, yo, por lo menos, no tenga la impresión de que fue una realidad esta brecha de tiempo que se va abriendo entre nosotras.

Siempre su amiga

Elisabeth

S/C Paseo Bonanova, 53.

Barcelona $^{7}$

5 Este libro, además del prólogo de Gabriela Mistral, titulado "Carmen Conde, contadora de la infancia", contó también con las ilustraciones de Norah Borges. Además, en 1936, Júbilos fue declarado libro de lectura en las Escuelas Nacionales. Este es otro ejemplo de red de colaboración entre autoras (Garcerá, 2018).

6 Carta de Elisabeth Mulder a Gabriela Mistral. Biblioteca Nacional de Chile, signatura: 9047.

7 Carta de Elisabeth Mulder a Gabriela Mistral. Biblioteca Nacional de Chile, signatura: 9074. 
Tras la publicación de Sinfonía en rojo, Elisabeth Mulder, ya viuda, publicó el poemario La hora emocionada (1931), también en la Editorial Cervantes. En este tan solo encontramos una emotiva dedicatoria del libro a su padre: "Dedico este libro a mi padre, quien desde mi infancia me alentó en la noble devoción del Arte. En recuerdo a las horas de desesperanza, en que solo su fe me instó a seguir adelante. E. M.". Dos años después, publicó en Atenas A. G. su obra Paisajes y meditaciones (1933), en la que ya no incluyó ningún elemento paratextual. No obstante, la década de 1930 fue importante en el devenir literario de Elisabeth Mulder, pues en ella publicó sus dos primeras novelas: Una sombra entre los dos (1934) y La historia de Java (1935). Fue su vocación novelística posterior la que logró que se consagrara como escritora y que se profesionalizara su escritura. De hecho, Consuelo Berges, que mantuvo una dilatada y estrecha amistad con ella", consideró la etapa poética de Mulder como su "prehistoria lírica" (Mañas 1988: 77). En relación con sus redes de apoyo y colaboración, resulta significativo que, precisamente, a partir de su primera novela, se abra su correspondencia con Carmen Conde. Así, en la primera carta conservada, que Mulder envió a la escritora cartagenera el 9 de julio de 1934, esta le indica que:

Mi querida Carmen:

Una vez más, perdóname estos largos silencios. Yo estoy siempre cerca de ti por el pensamiento, también a veces, te siento a ti muy cerca, y me emociono pensando que eres buena y vienes a buscarme. Y aun así, me callo. Perdóname.

Por desgracia para mí, y para mi vida, yo soy un ser ilógico que huye del propio bien con ese orgullo triste de los tímidos incurables. ¿Lo sabías tú que yo era tímida? No lo sospecha nadie. Y si yo no te quisiera mucho, no te haría esta confesión mortificante. La hago, por eso, porque te quiero mucho y porque a ti se te puede decir todo, que eres sensible y luminosa, con claridad de claridades. ${ }^{9}$

Podemos comprobar de qué forma el componente afectivo de estas redes de apoyo y solidaridad fue relevante para unos sujetos autorales cuyo paso a la esfera pública se percibía con recelo. De este modo, respecto al último libro de poemas que Conde acababa de publicar $^{10}$, Mulder le indica que:

Hoy, domingo, he estado leyendo tu Júbilos por segunda vez. No sabes tú cuánto y qué hondamente me gusta este libro. Toda tú estás en él, con tu pensamiento "plástico", con tu sobriedad y tu mesura. Es raro que una mujer haga obras así, duras y transparentes como un diamante. Cada faceta de tu libro da un trallazo de luz. Además, ¡qué léxico flexible y ceñido, qué construcción elegante, qué

8 Durante nuestra visita al archivo de Elisabeth Mulder en Barcelona, a la que ya nos habíamos referido, pudimos constatar la amplitud del epistolario intercambiado entre ambas, que permanece inédito.

9 Carta de Elisabeth Mulder a Carmen Conde. Patronato Carmen Conde-Antonio Oliver, signatura: 016-01558.

10 Véase nota al pie 5. 
movilidad y que justeza! Con el corazón te aplaudo esta obra; con el corazón te deseo todo el éxito que ella y tú merecéis.

Escríbeme. No me dejes tenderte la mano vanamente a través de la distancia.

¿Y vernos? ¿Cuándo? ¿Preparas algún viaje a Madrid? Yo tal vez vaya en octubre o noviembre. ¡Si pudiéramos vernos! Algún día he de ir a tu Cartagena, a vivir tu atmósfera.

Un abrazo muy apretado de esta amiga que te quiere tanto como te admira, y te admira con plenitud de fervor.

Elisabeth Mulder ${ }^{11}$

No obstante, la amistad entre ambas debió ser anterior, gracias a la dedicatoria manuscrita que Mulder dirigió a Conde en su libro La hora emocionada (1931), que dice así: "Para la poetisa Carmen Conde. En recuerdo de una rápida e intensa amistad que deja en mi huellas inolvidables / Elisabeth Mulder. 1932"12. Asimismo, también le dedicó su ejemplar de Paisajes y meditaciones (1933): "Para Carmen Conde de Oliver, dilecta amiga. Con el cariño y la admiración de Elisabeth Mulder"13. De nuevo, a través de esta amistad o la de Consuelo Berges con ambas, somos capaces de percibir cómo, a pesar de la distancia, el apoyo afectivo entre las autoras de finales de la Edad de Plata se convirtió en un elemento indispensable para su autopercepción autoral.

\section{3. "Una nueva hija de la poesía": Ana María Martínez Sagi, entre EL DEPORTE, EL PERIODISMO Y LA POESÍA}

El 17 de mayo de 1930, en el diario La Noche de Barcelona, Elisabeth Mulder publicó una reseña titulada "Una mujer que canta", a propósito de la aparición el año anterior del primer poemario de la barcelonesa Ana María Martínez Sagi, Caminos (1929), que bien podría haber servido de prólogo para el mismo, no solo por su belleza literaria, sino por la defensa que Mulder hace tanto de la obra como de su autora. En el texto, Mulder afirma que:

De vez en cuando, entre la cabalgata de amazonas surge una musa. De momento, detenida por la sorpresa, la cabalgata hace un alto en el camino y se para "a ver qué es aquello". Una musa... [...] Las amazonas, antes de lanzarse a galope por las rutas congestionadas, estallantes bocinazos, contemplan por última vez a la hermana dispar cuya audacia está en el verbo y cuya fuerza en el ideal, a la cantora que surgió Dios sabe cómo, en un ambiente poco propicio, de una semilla de época ingrata a las musas, en un momento discordante, al don del jazz universal del presente. [...] Con razón las amazonas comentan el caso; allí, de entre ellas, salió misteriosamente una nueva hija de la Poesía, cuando ya tanto se había generalizado la creencia de que la Poesía se había convertido al maltusianismo.

Hoy, la musa que han visto las amazonas se llama Ana María Martínez Sagi (en

11 Carta de Elisabeth Mulder a Carmen Conde. Patronato Carmen Conde-Antonio Oliver, signatura: 016-01558.

12 Patronato Carmen Conde-Antonio Oliver, signatura: 00615.

13 Patronato Carmen Conde-Antonio Oliver, signatura: 00651. 
Prada 2018: 329).

Tras la presentación de Martínez Sagi mediante este alarde literario de Mulder, esta apunta a su cualidad poética como innata. Además, apunta que la poeta es:

\begin{abstract}
Demasiado joven y demasiado inteligente para no ser en lo físico y en lo social una mujer de su tiempo, esta cantora dice sus rimas con cierta timidez, como consciente del espectáculo de anacronismo que está ofreciendo. Pero se está o no se está ungido por el quid divinum del que hablaba Horacio, y cuando se está no hay fuerza humana que destruya la esencia rara. Así, pese a su educación y a sus tendencias modernas, se ahonda un poco en Ana María Martínez Sagi y la lirófora aparece. Bajo su dinamismo de muchacha sanamente entregada al amor del deporte y al culto de la actividad, se adivinan los grandes silencios líricos de un espíritu contemplativo. Y un gran apasionamiento también (en Prada 2018: 329-330).
\end{abstract}

El apoyo de Elisabeth Mulder a Ana María Martínez Sagi a través de esta reseña fue manifiesto. Mulder no dudó en promulgar la imagen como mujer moderna de Martínez Sagi a la que ya nos habíamos referido, puesto que la vinculación de Martínez Sagi con el deporte iba más allá de la afición. De hecho, formó parte del Club Femení i d’Esports de Barcelona, que fue inaugurado el 14 de octubre de 1928 como la primera entidad exclusivamente femenina dedicada al deporte; se trataba de un espacio que aspiraba también al cultivo de la cultura a través del ocio y de la conversación (Real Mercadal 1998: 22). De este modo, Mulder señala que:

[...] es así Ana María Martínez Sagi, muy antigua y muy moderna, como en el tan citado verso de Rubén.

En estos momentos en que la mujer, recién liberada de las odiosas tiranías y del peso feroz del convencionalismo y la tradición, ha dedicado sus energías a las actividades más violentas - como consecuencia, sin duda, de la formidable reacción producida-, el advenimiento de una poetisa resulta de más en más extraordinario, por parecer casi anómalo que una mujer dotada de buen cerebro no se esfuerce en imponerle derroteros nuevos y lo dedique a la política, o a las finanzas, o a la aeronáutica, o a cualquier profesión "masculina", es decir que lo aparte del feminismo para dedicarlo a la feminidad, ya que, aunque se suela creer lo contrario, ninguna actividad mental y espiritual más propia de la mujer que esta de escribir versos. Cuando se cuenta, claro, con el quid divinum... ¡Y qué espectáculo tan sedante el de una mujer que canta, entre tanta mujer que grita! (en Prada, 2018: 332).

No obstante, uno de los mayores problemas que nos hemos encontrado a la hora de abordar la figura y la obra de Martínez Sagi ha sido la falta casi total de bibliografía sobre su devenir vital. En este sentido, debemos indicar que, en el año 2000, Juan Manuel de Prada publicó su libro Las esquinas del aire. En busca de Ana María Martínez Sagi, en el que, como su propio título indica, relató la investigación que llevó a cabo para dar con la poeta, cosa que consiguió aunque esta se encontraba ya en plena vejez, por lo que no pudo ver publicado el libro sobre su vida. De Prada, redactó una novela que oscila entre la ficción y la realidad. Por ello, es complicado conocer la veracidad 
documentada de su relato, para aplicarlo en una investigación académica como la que nos ocupa. En el citado libro incluye unos últimos capítulos que surgen de unas supuestas grabaciones en las que la autora ofreció su peripecia vital. Si tomamos como verídico lo expuesto por De Prada en su introducción a una antología de poesía y prosa de Elisabeth Mulder, fue la publicación de la anterior reseña de Mulder lo que provocó que esta y Martínez Sagi se conocieran, como puede leerse en el siguiente fragmento:

En aquel mismo año publiqué yo mi primer libro de poesías, Caminos. Envié un ejemplar al periódico donde la supuesta Elisabeth Mulder asumía la crítica literaria y esperé. Esperé con impaciencia y gran curiosidad. Apareció, pocos días después, una larga crónica que todavía hoy sigo considerando como la más sagaz, profunda e inteligente de cuantas se escribieron entonces. Haciendo gala de un don de observación y de intuición asombroso, Elisabeth Mulder puso claramente de manifiesto todos los resortes secretos de mi obra, trazando un retrato psicofísico de la autora perfectamente exacto. Le testimonié mi agradecimiento en una carta a la que contestó con una invitación para ir a verla a su casa (en Prada 2018: XXIII).

Al contrario que Elisabeth Mulder, Ana María Martínez Sagi sí eligió rodearse de dos elementos paratextuales, un prólogo y un epílogo, para su presentación en el campo cultural catalán. El primero fue un prólogo de la periodista, escritora y dramaturga Sara Álvarez-Insúa (1901-1985), hermana del novelista y periodista Alberto ÁlvarezInsúa (1883-1963), del que cabe destacar tan solo el último párrafo, en el que su autora indica que:

Caminos es un libro impecable. Heine, Musset, Bécquer, Rosalía, Rubén, Nervo, son los Maestros de Ana María, que es un poeta moderno sin modernismo, femeninos son feminismo. Ascendencia luminosa que da aristocráticos cuarteles a la nueva Musa, que, al sentirlo hace la consagración del amor, contra el cual muchos insensatos levantan pendón de guerra, sin saber que solo morirá cuando muera el universo (en Martínez Sagi 1929: 12).

Como indicábamos antes, habría sido más acertado como presentación en la literatura de Ana María Martínez Sagi la reseña literaria de Elisabeth Mulder, que estas palabras de Sara Álvarez-Insúa, en las que solo destaca el amor como leitmotiv poético de su autora. Por ello, el epílogo de Regina Opisso de Llorens (1879-1965) resulta un poco más conveniente, puesto que aborda no solo algunos de los temas principales de la poesía de Martínez Sagi, sino también su faceta de deportista ${ }^{14}$, a la que ya nos habíamos referido, y periodista, por lo que refuerza su imagen de mujer moderna. Así, Opisso señala que:

14 En este sentido, cabe apuntar que, en 1931, Ana María Martínez Sagi estableció un record femenino en España de lanzamiento de jabalina de 20,6 metros y, además, fue la primera mujer que ocupó un puesto directivo en el Fútbol Club Barcelona (Nell Warren, 2007: 142-143). 
Y no obstante ser Ana María una mujer ultra-sensitiva es a la vez una fémina ultra moderna, que ama los deportes y los practica con singular entusiasmo.

El tenis es su juego preferido. Prodigiosa raquetista, la hemos visto bajo nuestro cielo de añil, corriendo y agitando en alto la raqueta como si fuese una gran ala de mariposa

Excelente nadadora, ama el mar y se sumerge en sus aguas sin temor, como otra Anita Kenllerman. Así es Ana María, la esquiadora gentil devota de la nieve y de la sombra oscura de los bosques; la excursionista que conoce la cinta blanca de todos los caminos; así es esta mujercita que escribe versos, redacta interviús y escribe artículos con una prosa limpia y fluida como un madrigal (en Martínez Sagi 1929: 92-93).

Sin embargo, parece que Opisso, para contrarrestar lo que podría verse como un exceso de masculinidad en las aficiones de Martínez Sagi para los patrones de la época, se siente en la obligación de resaltar la feminidad de la poeta, a la que califica como “[a] rtista exquisita es esta mujercita tan mujer, tan femenina, esta poetisa que al asomarse a la vida ya sabe tanto del dolor de amar; que tiene el alma dolorida" (en Martínez Sagi 1929: 93). Respecto al resto de elementos paratextuales de la obra, la poeta tan solo incluyó dos dedicatorias de poema. Por un lado, a la niña prodigio del piano Giocasta Coma y, por el otro, precisamente, a Regina Opisso, a quien dedicó el poema "Una amiga", como un homenaje a la escritora y del que puede desprenderse su propia amistad.

La elección de estas dos autoras para abrir y cerrar el libro de Martínez Sagi, como en los anteriores casos, no es casual. Ambas pertenecían a la nómina de escritoras que comenzaron en esos años a publicar sus relatos en la prensa y en revistas, como por ejemplo Lecturas, junto a otras como Carmen de Icaza, Celia de Luengo o la propia Elisabeth Mulder. Precisamente, la amistad entre Mulder y Martínez Sagi se estrechó tanto que, cuando esta publicó su segundo poemario, Inquietud. Poesías (1932), Mulder elaboró un "retrato psico-físico de la autora" en verso, dividido en tres cantos: "Perspectiva", "Forma" y "Fondo". En el primero de ellos, pese a que no renuncia a la rima, como es característico en la poesía de Elisabeth Mulder, el contenido sí sorprende por su modernidad y la concatenación de imágenes, que son producto del profundo conocimiento que su autora tenía de Ana María Martínez Sagi en esa época. El poema dice así:

Sobre un fondo de Trianón... No.

Siglo xx. Rascacielos. Espítiru en catalepsia.

New-York. La obsesión del "yo".

Freud. Asepsia.

Nueva versión del histerismo.

Ya no hay Dama de las Camelias.

Ya todos los lagos sirven al nudismo.

Ya no tienen donde morir las Ofelias. 
El corazón bien amordazado y esposado por "policemen". El arte deshumanizado y la humanidad también.

Panorama de la post-guerra. Dólares. Cinismo. Estragos. La banca del sentimiento cierra: Está en suspensión de pagos.

Galería y taquilla. Sólo prestarle importancia a la cifra y la cabeza. Siglo XX. ¡Qué esfuerzo cuesta darle a la vida un poquito de belleza! (en Martínez Sagi 1932: 10).

En la segunda composición prologal, "Forma”, Mulder alude a la juventud de Ana María hasta "empequeñecerla", en un gesto por marcar su ingenuidad e inocencia, frente a ese ritmo frenético de siglo XX que aducía en la anterior composición. En el poema pueden leerse los siguientes versos:

Siglo XX... Pero tú, tú Ana María, perteneces a todos los siglos, porque tú eres poesía.

Y caminas alada. Y la emoción brota bajo tus plantas, esa emoción que buscas y que encuentras, que haces tuya y que cantas.

"Pequeña Ana María, clara y gentil..." ¡Ah, sí, pequeña Ana María, tú eres todo abril! Primavera está en ti con arraigo profundo, como está en flor la síntesis del mundo. Tu alígera sandalia deja sonora huella, $\mathrm{y}$ tu juventud es una rima más, rotunda y bella. (en Martínez Sagi 1932: 10).

El tercero y último de los poemas que componen el prólogo de Mulder al libro de Martínez Sagi, "Fondo", es el más emotivo de todos, hasta convertir su labor poética en un acontecimiento rodeado de misticismo. El poema comienza con una bendición:

...Y bendita tú seas.

Bendita tú que esparces un puñado de estrellas sobre las cosas feas de la vida. Bendita seas tú que dices palabras milagrosas y bellas, con aroma de nardos y fulgor de centellas. Bendita seas. Tú, que sientes y labras y palpitas y creas, 
¡bendita seas!

Profunda y sensitiva.

Tu alma — lava impalpable — se derrama

por las vertientes de la vida.

Te has hecho toda llama,

¡oh lámpara votiva!

Te has hecho toda llama...

Acaso, te has hecho toda herida.

(La espina que desgarra

deja abierto un resquicio

por donde se evapora la sonrisa.

Mas luego...

Tras nocturna penuria

viene el oro del sol,

$\mathrm{y}$ tus manos se tienden, trémulas

de celeste ambición).

La voz de tu alma es pura

y desnuda, sin un solo reflejo

que empañe la armonía de su cuerda.

Solo tu acento de mujer acierta

a darle ese temblor a la materia.

La mujer es mujer... Compendio suave

del bien y el mal disperso por la tierra.

Pero el alma no sabe de locuras.

Pero el alma, asexuada, es siempre buena.

Tu alma está es cada verso de tus rimas

y en casa vibración de tus ideas.

¡Oh, tú, que das tu alma, que golpeas

con tu alado talón las altas cimas!

¡Bendita seas! (en Martínez Sagi 1932: 11-12).

No obstante, y pese a la íntima conexión de ambas autoras, como se puede desprender de este último poema que, sin duda, debía captar, al menos, la extrañeza del lector ante la obra, Elisabeth Mulder decidió, tras un viaje de ambas a Alcudia en Mallorca, dar por finalizada la amistad "antes de que tomase derroteros incómodos" (Prada 2018: xxvii), tras lo cual Ana María Martínez Sagi se dedicó por completo a su labor como periodista. Y esos derroteros incómodos, a los que Prada se refiere, no son otros que el establecimiento de una relación sentimental entre ambas escritoras ${ }^{15}$.

\section{Dos autoras y UNA Red Más allá de la Edad de plata (A MOdo de CONCLUSIÓN)}

Tras la Guerra Civil, Mulder siguió afincada en su casa de Barcelona dedicada a la novela. No obstante, en 1949 publicó su último poemario, Poemas mediterráneos,

15 Véase nota al pie 18. 
que estaba dedicado "A Enrique Dauner Mulder, mi hijo"16. Fruto de la red de personalidades que supo forjar a su alrededor, como ya vimos, surgió el pórtico de esta obra, elaborado por la escritora Concha Espina (1869-1955) que, en ese momento de su trayectoria, ya se encontraba completamente consagrada. Unos años antes, en 1946, escribió a Gabriela Mistral una carta con motivo de su galardón como Premio Nobel de Literatura, en la que puede constatarse la lejanía que existía entre ambas escritoras, como había predicho Mulder en su última misiva a la poeta chilena de 1938. Dice así:

9-IX-1946

Querida Gabriela:

Me dirijo a usted sin tener la seguridad de que usted recuerde mi nombre. Nos conocimos hace años en Barcelona, han ocurrido muchas cosas y el tiempo es posible que haya borrado enteramente mi rostro de su recuerdo. Yo sí la he recordada a usted. Siempre. Tenemos amigos comunes —entre ellos a Ginés de Albareda- y continuamente he preguntado por usted y he seguido su paso. A Estocolmo la telegrafié, felicitándola. ¿Recibió mi gozo de saber su universalidad reconocida?

Tengo en mi poder unos manuscritos de usted, unos versos, probablemente a estas fechas ya publicados. Me los envió desde Madrid ¿recuerda? Me dijo usted que podría devolvérselos cuando volviéramos a encontrarnos, pero no nos hemos encontrado más, ni quizás no encontremos, y estos manuscritos, depósito preciosos, continúan en mi poder. ¿Cuál es su deseo respecto de ellos, Gabriela? ¿Quiere que siga conservándolos - lo hago con gran orgullo- o que los ponga nuevamente en sus manos remitiéndoselos?

Recuerda usted aquel pueblecito del litoral catalán, Caldetas, donde pasamos una tarde buscando para usted una caseta frente al mar? Pase el día de ayer allí y por la tarde me senté a la misma mesa del pequeño restorán donde en aquella ocasión estuvimos fumando cigarrillos y charlando hasta que llegó el tren. Mi recuerdo, ayer, en aquel lugar, la evocaba de una manera viva y fuerte, empujando al tiempo, haciendo retroceder todos estos años, todos estos silencios, y su imagen indirecta tenía la plasticidad cálida, de compañía, y de presencia. ¿Es esto lo que me hace escribirla hoy? Es posible, y aún a riesgo de que la ausencia me haya cubierto de sombra y usted deba buscar mucho en su memoria para encontrar, y acaso sin encontrar, a esta lejana amiga.

Elisabeth Mulder ${ }^{17}$

Precisamente, en el archivo de Gabriela Mistral en la Biblioteca Nacional de Chile, se conserva una carta de Ana María Martínez Sagi de ese mismo año escrita desde París en la que, entre otras cosas, recuerda el día en que conoció a la poeta chilena en la Residència Internacional de Senyoretes Estudiantes de la Generalitat de Catalunya. A continuación, trascribimos el documento en su totalidad, en el cual podemos leer lo siguiente:

16 El ejemplar que consultamos para este estudio, perteneciente al archivo personal de la escritora en Barcelona, contiene una dedicatoria manuscrita a su hijo en la que puede leerse: "A Enrique Dauner Mulder, mi hijo. Y suprema cima de mi vida. Su madre Elisabeth Mulder".

17 Carta de Elisabeth Mulder a Gabriela Mistral. Biblioteca Nacional de Chile, signatura: 9104. 
París 27 de enero de 1946

Querida Gabriela: Tal vez las numerosas recepciones oficiales hayan terminado ya y tal vez después de haber prodigado su proverbial gentileza y haber observado, con curiosidad, ese singular mundillo de las letras, querrá usted recibir [a] esta periodista y poeta español [sic], arrancado a su dulce tierra de Cataluña, desde hace siete años. La revista Per Catalunya órgano de los intelectuales catalanes en el exilio, solicita unas palabras suyas. ¿Quiere usted atender este ruego y permitir, que por segunda vez, vaya a estrecharle la mano?

Durante su estancia en la Residencia de Pedralbes — “la casa blanca de cien puertas, brilla como ascua a mediodía..." - como miembro oficial de la Comisión de Cultura de la Generalidad, acudí a una de las recepciones que aquella le ofreció. Aunque solo sea para resucitar unos instantes aquel feliz recuerdo, suplico a Usted acceda a mi petición.

En espera de su respuesta, reciba querida y admirada Gabriela, con mi profunda estima, mi más cordial saludo

Ana María Sagi

59, rue Froidevaux Paris (14)

De este modo, podemos conocer con certeza que Martínez Sagi se vio abocada a un exilio que condujo sus pasos hasta Francia y, posteriormente, a Estados Unidos. La única evidencia suya manuscrita que hemos podido hallar, además de la misiva a Gabriela Mistral, son sus cartas inéditas a Carmen Conde, con la que se puso en contacto en 1949 para que colaborase con la Revista Católica de Poesía y Literatura que se publicaba en Francia y a cuya redacción Martínez Sagi perteneció ${ }^{18}$. Lo relevante de estas misivas es el testimonio desgarrador cuando, tras un viaje a España desde Estados Unidos, la poeta catalana constató su profundo desarraigo de un país y de una familia que no iban a perdonar su modernidad, su ideología y su libertad. De este modo, en una misiva fechada el 27 de mayo de $1969^{19}$ en el Puerto de Andraitx, Martínez Sagi explica cómo:

[...] Salí hará un par de meses, huyendo positivamente de España, víctima de una abrumadora cantidad de vejaciones, insultos, ingratitudes, ruindades y decepciones de toda índole. La última y la peor, en Barcelona, mi ciudad natal.

18 Carta de Ana María Martínez Sagi a Carmen Conde. Patronato Carmen Conde-Antonio Oliver, signatura: 055-049.

19 Martínez Sagi envió a Carmen Conde su antología poética Laberinto de presencias, que había publicado ese mismo año en las Gráficas Celarayn de León. Se trata de una voluminosa edición que ella sufragó en su totalidad. El referido ejemplar presenta la siguiente dedicatoria manuscrita: "Para ti Carmen Conde gran poeta que admiro, este libro, en cuyo laberinto tú me hallarás fácilmente. / Ana María Sagi / Barcelona Junio 1969" (PCCAO, signatura: 423). Este volumen recoge sus poemarios inéditos: Canciones de la isla (1932-1936), País de la ausencia (1938-1940), Amor perdido (1933-1968), Jalones entre la niebla (1940-1967), Los motivos del mar (1945-1955) y Visiones y sortilegios (1945-1960). En este sentido, cabe mencionar que, en 2019 y bajo la edición de Juan Manuel de Prada, la Colección Obra Fundamental de la Fundación Santander publicó el libro La voz sola, que recoge un gran número de artículos periodísticos de Martínez Sagi, así como una selección de poemas de los poemarios a los que nos hemos referido hasta ahora. La novedad de este volumen es que también presenta algunos poemas de la autora dispersos en otras publicaciones y varios de dos poemarios inéditos: Noche sobre el grito y La voz sola, que recogen composiciones fechadas entre 1933 y 1970. En este último libro, precisamente, la autora vuelve al recuerdo de su idilio con Elisabeth Mulder (De Prada 2019) 
Hoy, después de treinta años de exilio, me entero de que no tengo familia, ni hogar, ni amigos, ni patria. He podido vivir y sobrellevar tanta miseria y tantos horrores, roída por el cauce de la nostalgia, porque la esperanza del regreso me mantuvo de pie. Desdichadamente, yo no tengo como tú, fe religiosa. El amor de lo Bello, el culto de la amistad y la paternidad humanas, el amor del Amor y el no haber cometido jamás un acto de cobardía, fueron y siguen siendo, mis únicos puntales. Ahora que compruebo que mi país era solo espejismo, la familia entera una entelequia, que yo no hago sino caminar sobre ruinas y escombros en una tierra poblada de estatuas, de viento, de almas viles y envidiosas, de escritores caníbales y de corazones desagradecidos y avariciosos, ¿qué podría decirte yo, querida Carmen? Estoy buscando en la luminosidad de esta isla, en la belleza sin par de sus paisajes, bálsamo y esperanza para mi corazón lacerado. Prosigo un patético y largo monólogo con fantasmas, tanteando ciega, entre sombras huidas, y nostalgias, me siento como un navío errante, sin deseo de abordar en Puerto alguno. ${ }^{20}$

Pese al distanciamiento definitivo entre Elisabeth Mulder y Ana María Martínez Sagi, hay que mencionar que se encuentra conservada en el archivo personal de Carmen Conde una carta de 1941 de Mulder a Amanda Junquera (1898-1986), por motivo de la elaboración de una antología de poetas españolas, en la que le facilitó datos de su antigua amiga, para que esta fuera incluida. Asimismo, en la segunda misiva que Martínez Sagi dirigió a Carmen Conde en 1949, en la última de las líneas añadidas tras la firma, le preguntó: "[¿]Conoce usted la obra poética de la novelista Elisabeth Mulder?". De este modo, podemos constatar que, pese a todo lo acontecido, a la lejanía y al tiempo trascurrido, las redes de colaboración y, sobre todo, el afecto, quizá por el recuerdo de otra época, continuaron operando décadas después de haber finalizado su amistad.

No obstante, antes de finalizar este estudio, cabe destacar la importancia de estudiar cada elemento paratextual en su particularidad, puesto que nos ha permitido desentrañar uno de los mecanismos mediante el cual las poetas de la Edad de Plata dieron su salto a la esfera pública e intentaron afianzar su lugar en el campo cultural. Además, al analizar las redes de solidaridad que establecieron entre ellas, hemos podido constatar que, pese a no conformar un grupo consolidado, el conocimiento que las unas tenían de las otras era mayor y más complejo de lo que se ha pensado hasta ahora. La afinidad colaborativa que se estableció entre Elisabeth Mulder y Ana María Martínez Sagi, debido a los acontecimientos biográficos entre estas últimas dos autoras, imposibilitó que esta alcanzase cotas literarias más elevadas. No obstante, analizar la relación que se estableció entre ambas nos ha permitido aproximarnos a las redes desarrolladas en otro núcleo cultural alejado de la capital, como Barcelona, en la que se fundaron otras instituciones femeninas propias aunque en constante diálogo

20 Carta de Ana María Martínez Sagi a Carmen Conde. Patronato Carmen Conde-Antonio Oliver, signatura: 171-053. 
con las de Madrid. Sin duda, los intercambios entre las asociaciones femeninas de ambas ciudades merecerán un estudio propio en el futuro.

\section{REFERENCIAS BIBLIOGRÁFICAS}

AA. VV., El autor enjuicia su obra, Madrid, Editora Nacional, 1966.

Cabré, María Ángeles, María Luz Morales, pionera del periodismo, Barcelona, La Vanguardia Ediciones, 2017.

Garcerá, Fran, “Dos poetas de orilla a orilla: epistolario inédito (1924-1988) de María cegarra Salcedo y Carmen Conde", María Cegarra Salcedo y Carmen Conde, Epistolario (1924-1988), Madrid, Ediciones Torremozas, 2018, pp. 9-38.

Lluch, Javier, "Los trabajos y los días de un editor rocambolesco: Vicente Blasco Ibáñez", Raquel Macciuci (ed.), La Plata lee a España. Literatura, cultura y memoria, La Plata, Ediciones del lado de acá, 2010, pp. 81-100.

Lluch, Javier, "Semblanza de Sociedad Editorial Prometeo (1914-1939)", en Biblioteca Virtual Miguel de Cervantes - Portal Editores y Editoriales Iberoamericanos (siglos XIXXXI) - EDI-RED, 2017: http://www.cervantesvirtual.com/obra/sociedad-editorialprometeovalencia-1914-1939-semblanza-849293/

Llanas, Manuel, L'edició a Catalunya: el segle XX (fins a 1939), con la colaboración de Montse Ayats, Barcelona, Gremi d'Editors de Catalunya, 2005.

Lázaro, Luis Miguel, “L'edició popular a Espanya. El cas de 1'Editorial Cervantes. Notes", Educació i Història: Revista d'Història de l'Educació, 22 (2013), pp. 33-63: http://revistes.iec.cat/index.php/EduH/article/view/75212/74967.

Mañas Martínez, María del Mar, La obra narrativa de Elisabeth Mulder, Tesis doctoral de la Universidad Complutense de Madrid, 1988.

Martínez Sagi, Ana María, Caminos, Barcelona, Industrias Gráficas Guinart, 1929.

Martínez Sagi, Ana María, Inquietud. Poesías, Barcelona, edición de la autora, 1932.

Martínez Sagi, Ana María, Laberinto de presencias. Antología poética, León, Gráficas Celarayn, 1969.

Mulder, Elisabeth, Sinfonía en rojo, Barcelona, Editorial Cervantes, 1929.

Prada, Juan Manuel de, “Introducción”, Elisabeth Mulder, Sinfonía en rojo. Prosa y poesía selecta, Madrid, Fundación Banco Santander, 2018, pp. XI-L.

Prada, Juan Manuel de, "Ana María Martínez Sagi: Un laberinto de presencias", Ana María Martínez Sagi, La voz sola, Madrid, Fundación Banco Santander, 2019, pp. XI-LXVI.

Real Mercadal, Neus, El Club Femení y d'Esports de Barcelona, plataforma d'acció cultural, Barcelona, Publicaciones de l'Abadia de Montserrat, 1998. 
Real Mercadal, Neus, Donailiteratura ala Catalunya de preguerra, Barcelona: Publicaciones de l'Abadia de Montserrat, 2006. 